\title{
Synthesis and Release of Interleukin 1 by Reoxygenated Human Mononuclear Phagocytes
}

\author{
S. Koga, * S. Ogawa, * K. Kuwabara, * J. Brett, * J. A. Leavy, * J. Ryan, * Y. Koga, * \\ J. Plocinski," W. Benjamin," D. K. Burns," and D. Stern* \\ ${ }^{*}$ Departments of Physiology and Cellular Biophysics and ${ }^{\ddagger}$ Medicine, Columbia University, College of Physicians and Surgeons, New \\ York 10032; and \$ Departments of Immunopharmacology and "Molecular Genetics, Hoffmann LaRoche, Nutley, New Jersey 07110
}

\begin{abstract}
To examine the possible involvement of cytokines in reperfusion injury, we have studied production of IL-1 by human vascular cells, including smooth muscle and mononuclear phagocytes. Exposure of cells to hypoxia $\left(\mathrm{pO}_{2} \approx 14\right.$ torr) followed by reoxygenation led to significant release of IL-1 only from the mononuclear phagocytes. Elaboration of IL-1 was dependent on the oxygen tension and duration of hypoxia (optimal at lower $\mathrm{pO}_{2} \mathrm{~s}, \approx$ 14-20 torr, and after $9 \mathrm{~h}$ ), as well as the time in reoxygenation (maximal IL-1 release at 6-9 h). Although a period of hypoxia was necessary for subsequent IL-1 production during reoxygenation of either peripheral blood monocytes or cultured monocyte-derived macrophages, no IL-1 release occurred during the hypoxic exposure. IL-1 released during reoxygenation was newly synthesized, and its production was triggered by the generation of oxygen free radicals, as it could be blocked by the addition of either allopurinol or free radical scavengers to cultures and could be stimulated in part by low concentrations of hydrogen peroxide or xanthine / xanthine oxidase. The potential pathophysiological effects of IL-1-containing supernatants from reoxygenated macrophages was shown by their induction of endothelial tissue factor and enhancement of endothelial adhesiveness for neutrophils, both of which could be blocked by anti-IL-1 antibody. The relevance of IL-1 to hypoxia/reoxygenation in vivo was suggested by the presence of circulating nanogram amounts of this cytokine in the plasma of mice during the reoxygenation period following a hypoxia. (J. Clin. Invest. 1992. 90:1007-1015.) Key words: ischemia • cytokine/monocyte
\end{abstract}

\section{Introduction}

When tissues become hypoxic, as occurs with hypoperfusion, and are subsequently reoxygenated, the tissue damage that oc-

Address correspondence to Dr. Shin Koga or Dr. David Stern, Department of Physiology and Cellular Biophysics, Columbia University-College of Physicians and Surgeons, 630 West 168th Street, New York, NY 10032.

Received for publication 10 December 1991 and in revised form 16 March 1992.

J. Clin. Invest.

(C) The American Society for Clinical Investigation, Inc. 0021-9738/92/09/1007/09 \$2.00

Volume 90, September 1992, 1007-1015 curs during reperfusion shares certain features with the inflammatory response (1-3). In view of the central role of certain cytokines, such as IL-1 and IL-6, and tumor necrosis factor/cachectin (TNF) $)^{1}(1,4,5)$, in the pathogenesis of the inflammation that occurs, we considered them as possible mediators in reperfusion injury. In this context, two recent studies have suggested a role for TNF; Colletti et al. (6) showed that a neutralizing antibody to TNF prevented tissue damage in hepatic ischemia, and Maury and Teppo (7) showed that plasma TNF levels were elevated in certain patients with myocardial infarctions.

Mononuclear phagocytes (MPs) have a central role in orchestrating the inflammatory response, especially in terms of their ability to elaborate cytokines $(1,5)$. To understand potential mechanisms underlying reperfusion injury, we examined whether MPs could produce inflammatory cytokines during hypoxia or reoxygenation. Our results show that human MPs synthesize and elaborate IL-1 after hypoxia/reoxygenation by a mechanism that involves the generation of oxygen free radicals early in the reoxygenation period. These data suggest that in addition to their role well-known role in causing tissue damage, oxygen free radicals can serve as a trigger initiating MP production of IL-1 during reperfusion, thereby mobilizing an inflammatory response.

\section{Methods}

Isolation and culturing of monocytes and vascular cells. The mononuclear fraction was isolated from human peripheral blood by density gradient centrifugation (8) (Histopaque 1077, Sigma Chemical Co., St. Louis, MO) followed by adherence to tissue culture plasticware for $4 \mathrm{~h}$ at $37^{\circ} \mathrm{C}$. Adherent cells were either used immediately (these cells were termed monocytes) or cultured for 10-14 d in RPMI 1640 containing $10 \%$ human serum and penicillin/streptomycin $(100 \mathrm{U} / \mathrm{ml}-100 \mu \mathrm{g} /$ $\mathrm{ml}$ ), and then used for experiments (the latter cells were termed monocyte-derived macrophages). Human umbilical vein endothelial cells (ECs) were prepared as described previously (9), and were used at passages 1-3. Human vascular smooth muscle cells were obtained from the aortic arch of cardiac transplant donors by the method of Gunther et al. (10) as modified by Colucci et al. (11), were characterized using a mouse monoclonal antibody to smooth muscle actin (Sigma Chemical Co.) (12), and were used at passages 2-5.

1. Abbreviations used in this paper: BHA, butylated hydroxyanisole; BHT, butylated hydroxytoluene; DTPA, diethylenetriamine pentaacetic acid; EC, endothelial cell; GAPDH, glyceraldehyde-3-phosphate dehydrogenase; LDH, lactate dehydrogenase; MP, mononuclear phagocyte; PCR, polymerase chain reaction; TNF, tumor necrosis factor. 
Hypoxia/reoxygenation of cells and measurement of oxygen free radical formation. Cell cultures were exposed to hypoxia by placing them in an hypoxia chamber at $37^{\circ} \mathrm{C}$ (Coy Laboratory Products, Ann Arbor, MI) (13). Where indicated, after exposure to hypoxia, cultures were returned to an atmosphere with ambient oxygen levels (fresh medium was added at the time of reoxygenation). Other agents were added to MP cultures at the time of reoxygenation, including allopurinol, butylated hydroxyanisole (BHA), butylated hydroxytoluene (BHT), desferrioxamine, diethylenetriamine pentaacetic acid (DTPA), or mannitol (all obtained from Sigma Chemical Co., except for desferrioxamine, which was obtained from Ciba Pharmaceuticals, Summit, NJ).

MP viability of hypoxic and reoxygenated cells was assessed by trypan blue exclusion, release of LDH ( the latter was determined using a kit from Sigma Chemical Co. according to the manufacturer's instructions), and general morphologic characteristics. ATP levels were determined using the luciferase assay (14), and protein synthesis was assessed by the incorporation of $\left[{ }^{3} \mathrm{H}\right]$ leucine $(15)$.

For certain experiments endothelial cells were exposed to xanthine/ xanthine oxidase (Sigma Chemical Co.) or hydrogen peroxide (Sigma Chemical Co.), and IL-1 activity in culture supernatants was measured. Formation of oxygen free radicals by macrophages on replacement into normoxia was determined by luminol (5-amino-2,3-dihydro-1,4 phthalazine dione)-dependent chemiluminescence (16).

Assays for cytokines: $I L-1, I L-6$, and TNF. IL-1 activity was assessed using the D10(N4)M cell line (17) on culture supernatants after centrifugation and filtration $(0.2 \mu \mathrm{m})$ to remove any debris. The limit of sensitivity of this assay was $<2 \mathrm{U} / \mathrm{ml}$. IL-1 activity could be neutralized by the IgG fraction derived from monospecific goat anti-humanIL $\alpha$ and $-\beta$ antisera (also see Fig. $1 C$ ). In experiments in which oxygen free radical scavengers/inhibitors were added to culture media (BHT, BHA, allopurinol, mannitol, DTPA, and desferrioxamine), controls performed with medium containing the indicated agent and exogenous IL-1 did not demonstrate inhibition of proliferation in the D10 assay. Similarly, the amounts of xanthine/xanthine oxidase and hydrogen peroxide used in our assays had no effect on assessment of IL-1 activity in the D10 assay. IL-1 antigen was measured in mouse plasma using a radioimmunoassay kit from Cytokine Sciences, Inc. (Boston, MA) according to the manufacturer's instructions. The limit of detection was $20-30 \mathrm{pg} / \mathrm{ml}$.

IL-1 antigen was detected by immunoprecipitation of metabolically labeled macrophage cultures. MPs were incubated in methionine/cysteine-poor Minimal Essential Medium (Gibco Laboratories, Grand Island, $\mathrm{NY})$, and then ${ }^{35} \mathrm{~S}-$ methionine $(0.2 \mathrm{mCi} / \mathrm{ml} ; 1,134 \mathrm{Ci} / \mathrm{mmol}$; New England Nuclear, Arlington, MA ) and ${ }^{35} \mathrm{~S}$-cysteine $(0.1 \mathrm{mCi} / \mathrm{ml}$; $1038 \mathrm{Ci} / \mathrm{mmol}$; New England Nuclear) were added either after $6 \mathrm{~h}$ in hypoxia ( $\mathrm{pO}_{2} \approx 14 \mathrm{mmHg}$ ), followed by $6 \mathrm{~h}$ in normoxia, or to normoxic cultures. After addition of radiolabel, MPs were incubated for an additional $6 \mathrm{~h}$ in the same environment (normoxia or hypoxia) to allow for labeling, and then supernatants or detergent lysates of the cells were subjected to immunoprecipitation with goat anti-human IL-1 $\beta$ antiserum (the antibody was generously provided by Dr. R. Chizzonite, Hoffmann-LaRoche, Nutley, NJ). Supernatant was collected, centrifuged, Triton X-100 $(0.05 \%)$ was added, and then the sample was incubated with the IgG fraction of anti-IL- $1 \beta$ antiserum. Cell lysates were prepared by scraping MPs into suspension, pelleting them by centrifugation, solubilizing the cell pellet, and then performing immunoprecipitation with anti-IL- $1 \beta$ antiserum in the presence of protease inhibitors. Immunoglobulin/immune complexes were precipitated with protein $\mathrm{G}$ suspension (Sigma Chemical Co.) and subjected to SDS-PAGE $(15 \%)$ (18), followed by autoradiography.

Measurement of IL-1 and TNF transcripts by polymerase chain reaction (PCR). The IL-1 $\alpha$ primers used for PCR were those described by Narayanan et al. (19), and the IL- $1 \beta$ primers were primer $15^{\prime}$ AAC GAG GCT TAT GTG CAC 3' (sense) and primer $25^{\prime}$ CAG CTT GTT ATT GAT TTC 3' (antisense). The TNF primers used for PCR were primer $15^{\prime}$ GAC AAG CCT GTA GCC CAT GTT G 3' (sense) and primer 2 5' TGA GTC GGT CAC CCT TCT CCA G 3' (antisense). The glyceraldehyde-3-phosphate dehydrogenase (GAPDH) primers used for PCR were primer 1 5' CCA TGG AGA AGG CTG GGG 3' (sense) and primer $25^{\prime}$ CAA AGT TGT CAT GGA TGA CC 3' (antisense). To compare transcript levels in MPs exposed to various oxygen concentrations, PCR was performed for 10, 15, 20, and 25 cycles. By analyzing product at each end point, approximate quantitative comparisons of initial target sequence could be made between different samples during the linear phase of the amplification reaction. Each $100-\mu 1$ reaction contained $3 \mu \mathrm{l}$ of cDNA, $200 \mu \mathrm{M}$ dNTP, equal amounts of sense and antisense primer (2.0 $\mu \mathrm{g}$ for GAPDH, $4.0 \mu \mathrm{g}$ for IL- $1 \alpha$, IL$1 \beta$, and TNF), and 5.0 U Taq polymerase (Perkin-Elmer Cetus, Norwalk, CT). This reaction mixture was aliquoted into four equal samples, each undergoing amplification for a specified number of cycles. After an initial denaturation step at $94^{\circ} \mathrm{C}$ for $7 \mathrm{~min}$, each cycle consisted of incubations at $94^{\circ} \mathrm{C}$ for $1 \mathrm{~min}, 55^{\circ} \mathrm{C}$ for $2 \mathrm{~min}$, and $72^{\circ} \mathrm{C}$ for 3 min. Products were analyzed on a $3 \%$ agarose gel and visualized under ultraviolet light by staining with ethidium bromide.

Elaboration of IL- 6 and TNF antigen into the supernatant of hypoxic/reoxygenated macrophages was determined by ELISA using kits from Genzyme (Boston, MA) according to the manufacturer's instructions. The limit of detection in these assays was $156 \mathrm{pg} / \mathrm{ml}$ and 20 $\mathrm{pg} / \mathrm{ml}$, respectively. For a positive control in the IL- 6 assay, macrophages were incubated with purified human recombinant IL-1 at concentrations of 5 and $10 \mathrm{ng} / \mathrm{ml}$ for $24 \mathrm{~h}$, and supernatants were harvested. For a positive control in the TNF assay, macrophages were incubated with lipopolysaccharide ( $1 \mu \mathrm{g} / \mathrm{ml}$; Sigma Chemical Co.) for indicated times, and supernatants were obtained.

Assessment of leukocyte-endothelial adherence, ELAM-1, and endothelial procoagulant activity. Assessment of leukocyte-endothelial interaction was performed on confluent monolayers of human umbilical vein ECs prepared in 96-well plates by the method described by Wright et al. (20). Tissue factor activity of EC monolayers was studied following a 6-h incubation with conditioned medium derived from either hypoxic, normoxic, or hypoxic/reoxygenated cells as described previously $(21,22)$.

In vivo hypoxia/reoxygenation in a mouse model. Mice were subjected to hypoxic conditions and reoxygenated using a controlled environment chamber (access to this chamber was generously provided by Dr. R. Stark, Department of Pediatrics). Animals were placed in the chamber and the system parameters were adjusted for a final oxygen concentration of $5-6 \%$ with the balance of the gas mixture made up of nitrogen. Over the first hour, the oxygen content of the atmosphere was reduced from ambient levels to $10 \%$, and over the second hour the oxygen content was further lowered to the range of 5-6\%. Reoxygenation was achieved by allowing the chamber to equilibrate with the ambient atmosphere. Mice were exposed to hypoxia alone or hypoxia followed by reoxygenation for varying times. Plasma samples were assayed for IL-1 antigen in the radioimmunoassay (see above).

Statistical analysis. Data were analyzed by single factor analysis of variance (see Figs. 1, 2, and 4-8). Posthoc comparisons of individual means were performed using the Tukey test. In each figure legend, the origin of the experimental data used for the statistical calculations, the points used for making comparisons, and $P$ values are indicated. Data shown are the mean \pm SD.

\section{Results}

Production of IL-1 by MPs exposed to hypoxia followed by a period of reoxygenation. Cultured vascular smooth muscle and monocyte-derived macrophages were exposed to hypoxia $\left(\mathrm{pO}_{2}\right.$ $\approx 14$ torr) followed by replacement into normoxia and studied for elaboration of IL-1 activity (Fig. 1, $A$ and $B$ ). No detectable 

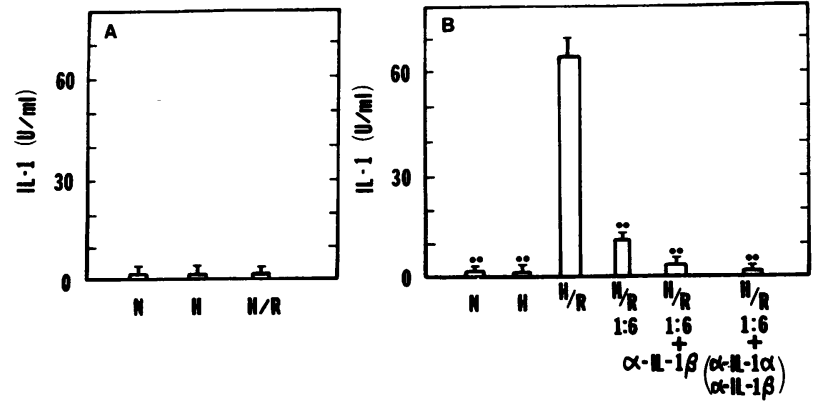

Figure 1. Effect of hypoxia and hypoxia/reoxygenation on the elaboration of IL-1 activity by $(A)$ smooth muscle cells, and $(B)$ macrophages. Cultures of human smooth muscle $\left(10^{6}\right.$ cells $)$ or macrophages $\left(10^{6}\right.$ cells) were washed with PBS, and then Medium 199, which had been preequilibrated with a gas mixture consisting of $\mathrm{pO}_{2} \approx 0$ torr, $\mathrm{pCO}_{2} \approx 40$ torr, and the balance made up of nitrogen, was added, and cells were placed in the hypoxia chamber $\left(\mathrm{pO}_{2} \approx 14\right.$ torr $)$. After $9 \mathrm{~h}$ of hypoxia, the medium was aspirated, fresh medium was added, and cultures were exposed to normoxia for an additional $6 \mathrm{~h}$. Other cultures were maintained in normoxia or hypoxia throughout the experiment $(15 \mathrm{~h})$. Aliquots of medium were then assayed for IL-1 activity as described in the text. $\mathrm{N}$, normoxia for $15 \mathrm{~h}$; $\mathrm{H}$, hypoxia for $15 \mathrm{~h} ; \mathrm{H} / \mathrm{R}$, hypoxia for $9 \mathrm{~h}$ followed by reoxygenation for $6 \mathrm{~h}$ (the medium tested in the IL-1 assay in the latter case was added on replacement in normoxia). Where indicated, conditioned medium was neutralized by the addition of goat anti-human IL- $1 \beta$ and/or antihuman IL-1 $\alpha$ antisera as described in the text (H/R $+\alpha$-IL-1 $\beta$ or $\alpha$ IL- $1 \alpha+\alpha$-IL-1 $\beta)$. Controls with nonimmune goat serum had no effect on IL-1 activity in conditioned media. Data shown represent two experiments with $n=6$ in $A$ and $n=4$ in $B$ (these studies used two different groups of macrophages and smooth muscle cells). There were no significant differences between the data groups in $A$. In $B$, there was a statistically significant difference between the bar $H / R$ and the bars designated by ${ }^{* *}(P<0.01)$.

IL-1 activity was observed in supernatants of hypoxic/reoxygenated smooth muscle cells in the D10 assay (Fig. $1 \mathrm{~A}$ ). Only the macrophages elaborated significant amounts of IL-1 activity (Fig. $1 B$ ). IL-1 activity produced by reoxygenated macro- phages was mainly neutralized by antibody to IL- $1 \beta$, although to achieve complete neutralization of the samples the presence of anti-IL- $1 \alpha$ antibody was also required (Fig. $1 B$ ). Elaboration of IL-1 by macrophages occurred in a time-dependent manner, depending both on the period of hypoxia and reoxygenation (Fig. $2 A$ ). Maximal IL-1 release occurred after 6-9 h in hypoxia followed by 6-9 $\mathrm{h}$ in normoxia, but lesser amounts of IL-1 were elaborated into the medium after shorter times, as little as $3 \mathrm{~h}$ of hypoxia and $1 \mathrm{~h}$ of normoxia. Release of IL- 1 also depended on oxygen tension during the period of hypoxia, being observed only at the lower levels of oxygen ( 21 and 14 torr) (Fig. $2 B$ ). Thus, exposure of macrophages to an atmosphere with very low levels of oxygen was necessary, but not sufficient, to result in IL-1 elaboration. A subsequent period of reoxygenation after hypoxia was also required.

To assess mechanisms responsible for release of IL-1 from the MPs under these conditions, it was important to determine if exposure to hypoxia/reoxygenation altered cell viability leading to release of IL- 1 as a consequence of damage. Exposure of macrophages to $\mathrm{pO}_{2} \approx 14$ torr for $18 \mathrm{~h}$, the longest time points employed in these experiments, did not affect cell viability based on several criteria: cells remained adherent to the growth surface and did not demonstrate increased uptake of the vital dye trypan blue, there was no increase in the release of LDH into the medium, ATP levels were $\approx 80 \%$, and overall protein synthesis was maintained at $\approx 80 \%$ the levels seen in normoxic controls. Subsequent exposure to normoxia also did not alter cell viability, based on these criteria. These data suggest that hypoxia/reoxygenation resulted in release of IL-1 by mechanisms not related to loss of cellular integrity with nonspecific leakage of intracellular contents into the medium.

In view of the time course for IL-1 release after reoxygenation, with its delay of $\sim 3 \mathrm{~h}$ before detection of significant amounts of cytokine activity in the medium, the possibility that IL-1 was being synthesized and then released was considered. Immunoprecipitation of metabolically labeled macrophage detergent lysates and supernatants from hypoxic/reoxygenated cultures with anti-IL- $1 \beta$ antibody demonstrated two bands on the autoradiograms most likely due to IL- $1 \beta$ (Fig. 3
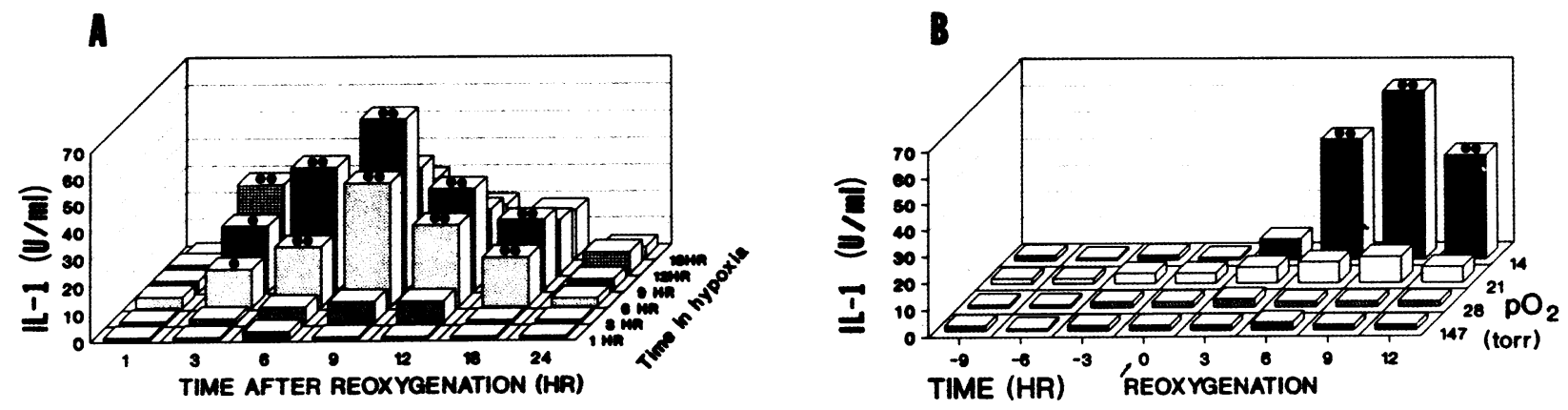

Figure 2. IL-1 production by macrophages subjected to hypoxia followed by reoxygenation: dependence on incubation times and oxygen concentration. $(A)$ Time course. Macrophages $\left(10^{6}\right.$ cells) were exposed to hypoxia $\left(\mathrm{pO}_{2} \approx 14 \mathrm{~mm} \mathrm{Hg}\right.$ ) for varying time periods, and then exposed to normoxia as indicated. Aliquots of conditioned media were removed and assayed for IL-1 activity. $(B)$ Oxygen dose-response. Macrophages $\left(10^{6}\right.$ cells) were exposed to an atmosphere containing the indicated partial pressure of oxygen for varying times (from -9 to $-3 \mathrm{~h}$ ), followed by incubation in normoxia (time $=0$ is the time of replacement into normoxia) for 3-12 h. Aliquots of conditioned media were removed and assayed for IL-1 activity. The mean of duplicate determinations from one experiment is shown. There is a statistically significant difference between macrophages in normoxia and those in hypoxia or hypoxia/reoxygenation as indicated: ${ }^{*}(P<0.05)$ and ${ }^{* *}(P<0.01)$. 
$A$, lysate and medium, $H R$ ): in cell lysates, a major band was observed with a relative molecular mass of $\approx 35 \mathrm{kD}$, which showed similar migration to that reported previously for the IL- $1 \beta$ precursor, and in supernatants, a diffuse band was observed with a relative molecular mass of $17-20 \mathrm{kD}$, which showed similar migration to that reported previously for the fully processed form of IL- $1 \beta(23,24)$. In contrast, little IL- $1 \beta$ was detectable in metabolically labeled samples derived from comparable numbers of normoxic and hypoxic macrophages (Fig. $3 A ; N$ and $H$ ). To determine if increased macrophage synthesis of IL-1 occurred in parallel with an increase in the level of mRNA for IL-1, experiments using the PCR were performed with primers for IL- $1 \alpha$ and IL- $\beta$ (Fig. $3 B$ ). In each case, no significant difference in levels of transcripts were observed in the normoxic and hypoxic/reoxygenated samples. Similar results were observed when the effect of hypoxia/reoxygenation on TNF $\alpha$ transcripts was studied using PCR (Fig. 3 $B$ ). Controls with GAPDH also showed bands of approximately equal intensity. Thus, enhanced production of IL-1 in hypoxic/reoxygenated macrophages was not accompanied by parallel changes in the level of mRNA for this cytokine relative to that found in normoxic conditions.

The role of oxygen free radicals in macrophage $I L-1$ release. Experiments to elucidate the stimulus for IL- 1 release from hypoxic/reoxygenated macrophages focused on the production of oxygen free radicals under these conditions (Figs. 4 and 5 ). The presence of the general free radical scavengers BHA and BHT simultaneous with reoxygenation blocked subsequent IL-1 production (Fig. $4 A$ ). In addition, allopurinol, an inhibitor of xanthine oxidase that has also been shown to be a hydroxyl free radical scavenger (25), prevented IL-1 production in a dose-dependent manner (Fig. $4 A$ ). Mannitol, the hydroxyl radical scavenger, also partially inhibited IL-1 production, as well as the chelators desferrioxamine and DTPA (26) (Fig. $4 \mathrm{~A}$ ). These results suggested the hypothesis that formation of oxygen free radicals, probably involving formation of the superoxide and hydroxyl free radicals during reoxygenation, facilitated by the presence of accessible transition metals (27), triggered IL-1 production. In support of this, addition of either xanthine/ xanthine oxidase or hydrogen peroxide to normoxic macrophages led to elaboration of IL-1 activity into culture supernatants, although the amounts were less than that observed with hypoxia/reoxygenation (Fig. 4, $B$ and $C$ ). This is probably due to the toxicity of these oxygen free radical generating systems, which also resulted in cell damage, especially evident at the higher concentrations of hydrogen peroxide $(\geq 1 \%)$.

The experiments with oxygen free radical scavengers suggested that exposure of macrophages to hypoxia/reoxygenation resulted in the formation of oxygen free radicals. Using a luminol-dependent chemiluminescence assay (16), formation of free radicals was measured during reoxygenation: they were evident within $5 \mathrm{~min}$ of replacement into normoxia, reached a maximum by $30 \mathrm{~min}$, and returned to levels close to the baseline within $3 \mathrm{~h}$ (Fig. $5 \mathrm{~A}$ ). Generation of chemiluminescence was largely prevented by adding either allopurinol or BHA just before reoxygenation of macrophages. These data implied that free radical production early in the reoxygenation period was

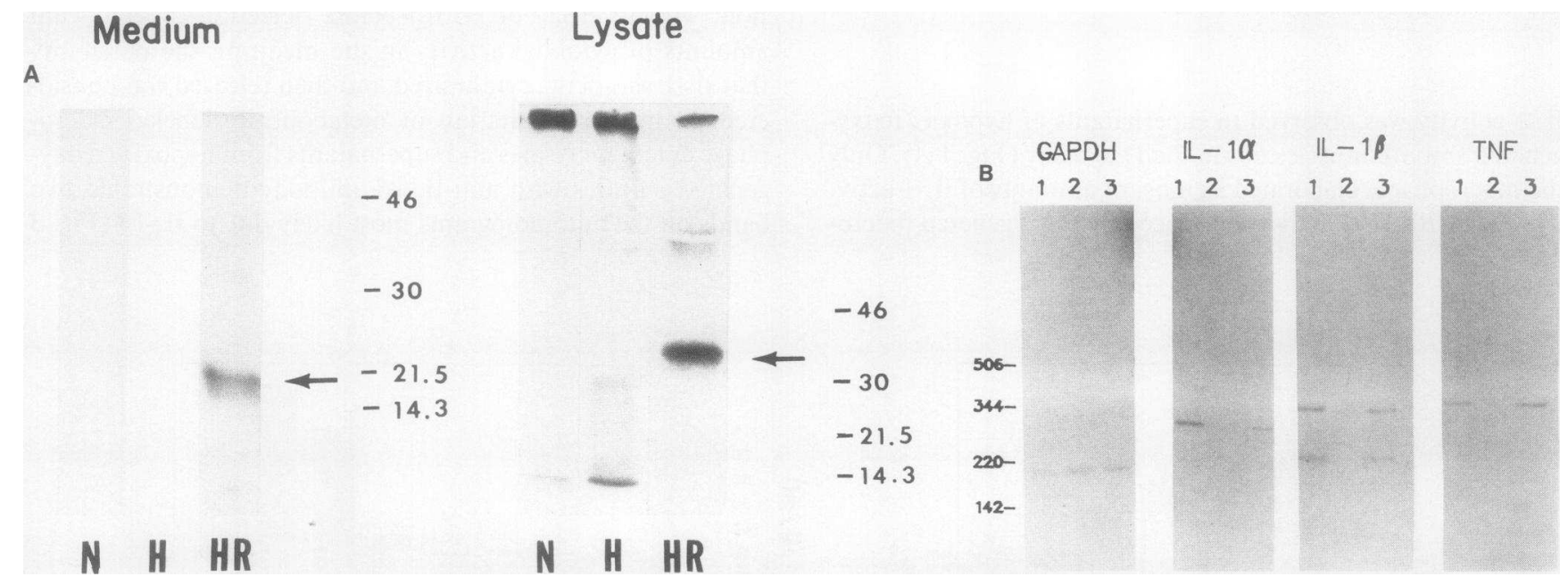

Figure 3. Immunoprecipitation and PCR analysis of IL-1 $\beta$ from conditioned media and cell lysates of macrophages: effect of normoxia, hypoxia, and hypoxia followed by reoxygenation. $(A)$ Immunoprecipitation. Macrophages were exposed to either normoxia for $12 \mathrm{~h}(N)$, hypoxia $\left(\mathrm{pO}_{2}\right.$ $\approx 14$ torr) for $12 \mathrm{~h}(H)$, or hypoxia $(6 \mathrm{~h})$ followed by normoxia for $6 \mathrm{~h}(H R)$. Cultures were metabolically labeled and immunoprecipitation of conditioned media and cell lysates with a monospecific antibody to human IL- $1 \beta$ was performed as described in the text. Nonreduced SDSPAGE (15\%) and autoradiography were performed. The two areas of the autoradiogram denoted by the arrows correspond to relative molecular masses of $\approx 35$ and $17-20 \mathrm{kD}$, based on the migration of standard proteins run simultaneously: ovalbumin $\left(\mathrm{M}_{\mathrm{r}} \approx 46 \mathrm{kD}\right)$, carbonic anhydrase $\left(\mathrm{M}_{\mathrm{r}} \approx 30 \mathrm{kD}\right)$, trypsin inhibitor $\left(\mathrm{M}_{\mathrm{r}} \approx 21.5 \mathrm{kD}\right)$, and lysozyme $\left(\mathrm{M}_{\mathrm{r}} \approx 14.3 \mathrm{kD}\right)$. (B) Amplification of macrophage mRNA by PCR. Cells were exposed to normoxic conditions for $(1) 8 \mathrm{~h},(2)$ hypoxia for $8 \mathrm{~h}$, or $(3)$ hypoxia $(7 \mathrm{~h}$ ) followed by reoxygenation for $1 \mathrm{~h}$. First-strand cDNA prepared from poly $\mathrm{A}^{+}$RNA served as template for PCR in combination with primers specific for glyceraldehyde-3-phosphate dehydrogenase $(G A P D H)$, IL-1 $\alpha$, IL-1 $\beta$, or TNF. Results shown are samples taken during the linear portion of the implication reaction: cycle 15 for GAPDH, cycle 20 for IL- $1 \alpha$ and TNF, and cycle 20 for IL- $1 \beta$. The photographic reverse image of ethidium bromide-stained agarose gels is shown for clarity of the faint bands. 

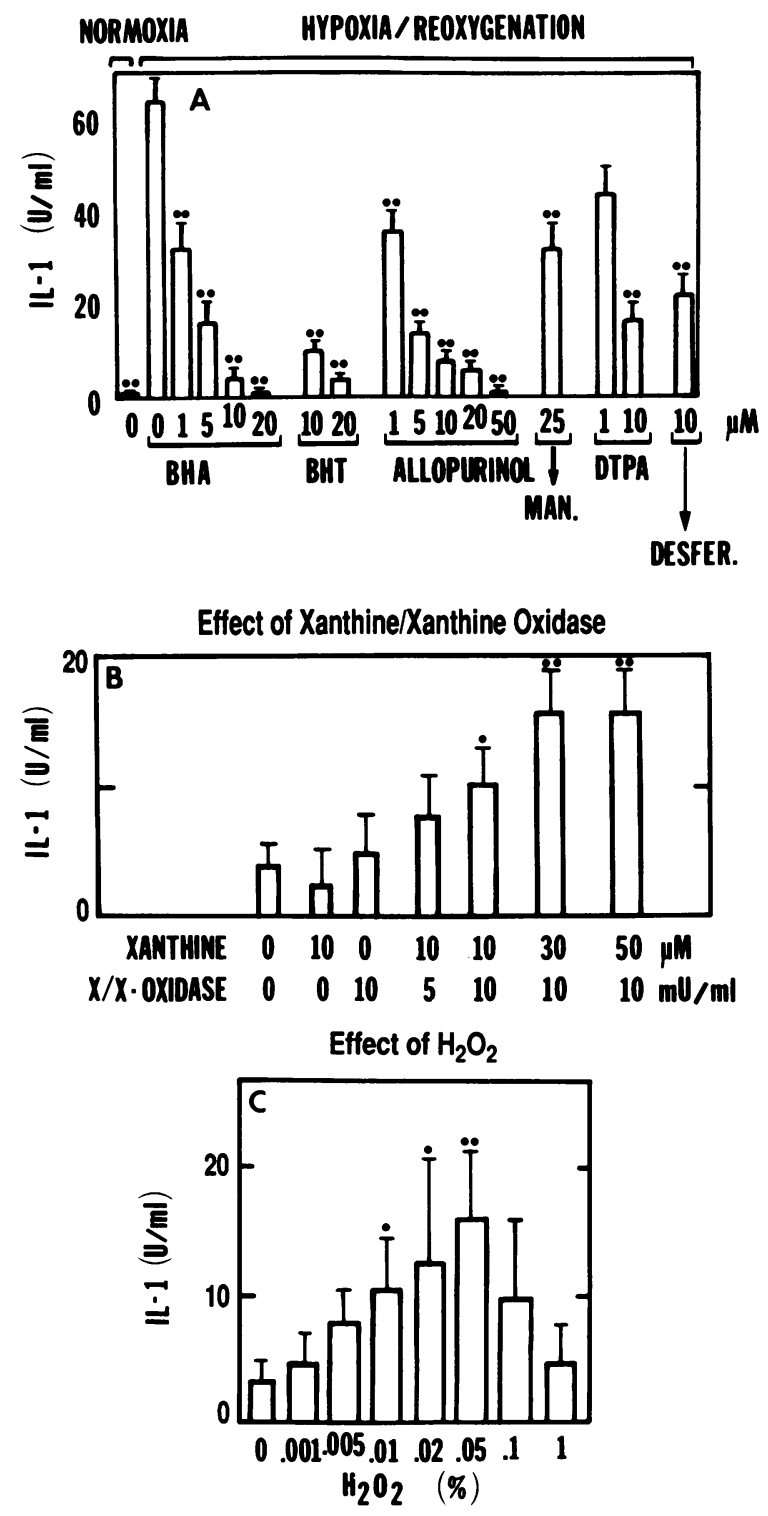

Figure 4. IL-1 production by macrophages: effect of oxygen free radical scavengers, transition metal chelators, and oxygen free radical generating systems. $(A)$ Effect of oxygen free radical scavengers and transition metal chelators. Macrophages $\left(10^{6}\right.$ cells $)$ were exposed to hypoxia ( $\mathrm{pO}_{2} \approx 14$ torr) for $6 \mathrm{~h}$ followed by $6 \mathrm{~h}$ in normoxia. Just before exposure to reoxygenation, either BHA (at the indicated concentration), BHT $(10,20 \mu \mathrm{M})$, allopurinol (at the indicated concentration ), $\alpha$-D-mannitol ( $25 \mathrm{mM})$, DTPA $(1,10 \mu \mathrm{M})$, or desferrioxamine (DESFER.; $10 \mu \mathrm{M}$ ) was added. At the end of the experiment, an aliquot of medium was obtained for IL-1 assay. ( $B$ ) Effect of incubation of normoxic macrophages with xanthine/xanthine oxidase on IL-1 elaboration. Macrophages ( $10^{6}$ cells) were incubated with xanthine oxidase ( $x$-oxidase) and/or xanthine $(x)$ for $6 \mathrm{~h}$ in normoxia. An aliquot of conditioned medium was obtained for IL-1 assay. $(C)$ Effect of incubation of normoxic macrophages with hydrogen peroxide on IL-1 elaboration. Macrophages ( $10^{6}$ cells) were incubated with hydrogen peroxide for $6 \mathrm{~h}$ in normoxia. An aliquot of conditioned medium was obtained for IL- 1 assay. In each case, the mean and SD is shown: $(A)$ one experiment with triplicate determinations; ( $B$ and $C$ ) data pooled from two experiments $(n=4)$. In $A,{ }^{* *} P<0.01$ compared with $\mathrm{H} / \mathrm{R}$ in the absence of added agents ( 0$)$. In $B$ and $C$, ${ }^{*} P<0.05$ and ${ }^{* *} P<0.01$ compared with macrophages incubated in the absence of added agents.
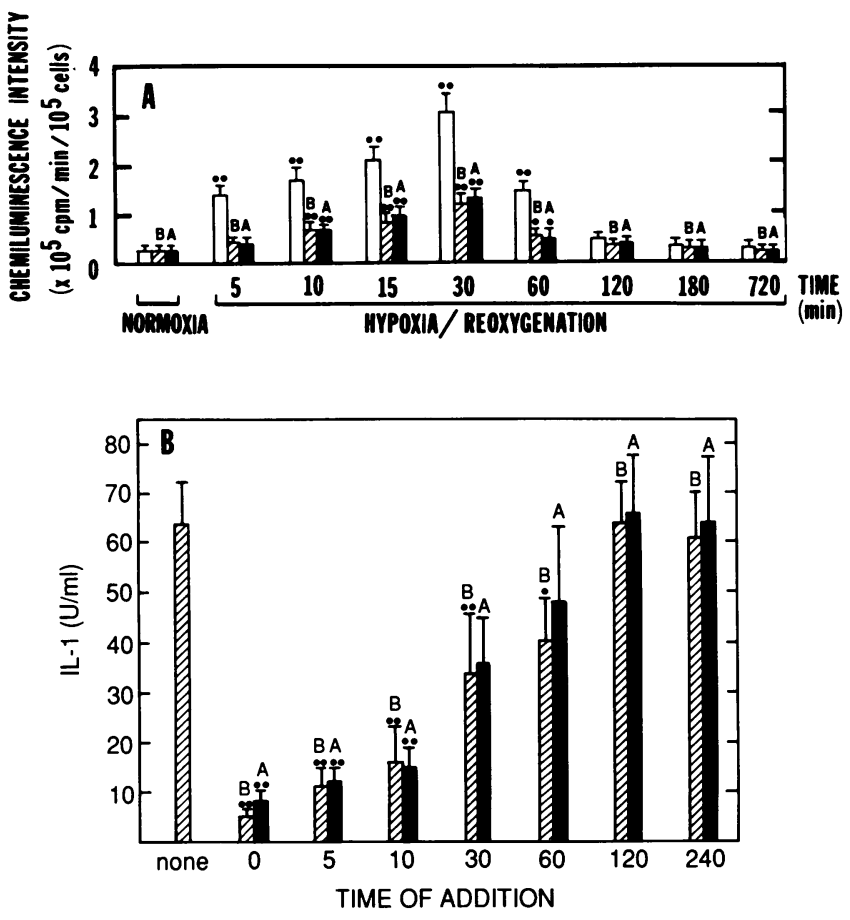

Figure 5. Oxygen free radical generation and IL-1 production by macrophages exposed to hypoxia followed by reoxygenation: effect of time of addition of BHA and allopurinol. $(A)$ Oxygen free radical generation by hypoxic/reoxygenated macrophages, as assessed using luminol-dependent chemiluminescence. Macrophages $\left(10^{6}\right.$ cells $)$ were exposed to hypoxia $\left(\mathrm{pO}_{2} \approx 14\right.$ torr $)$ for $9 \mathrm{~h}$ followed by normoxia as indicated. Starting at the time of reoxygenation ( time $=0$ ), aliquots of supernatant were withdrawn to detect luminol-dependent chemiluminescence ( open bars). In certain wells, either allopurinol ( $10 \mu \mathrm{M}$; closed bars $)$ or BHT ( $10 \mu \mathrm{M}$; cross-hatched bars $)$ was added just before reoxygenation, and samples were obtained for the IL-1 assay at the indicated times. $(B)$ Production of IL-1 activity by hypoxic/reoxygenated macrophages: effect of the time of addition of allopurinol or BHT. Macrophages ( $10^{6}$ cells) were exposed to hypoxia $\left(\mathrm{pO}_{2} \approx 14\right.$ torr) for $9 \mathrm{~h}$, followed by normoxia for $6 \mathrm{~h}$. Allopurinol $(10 \mu \mathrm{M})$ or BHT $(10 \mu \mathrm{M})$ was added just before reoxygenation (time $=0$ ) or at the indicated time after replacement of cultures in normoxia. Aliquots of culture media were obtained for IL-1 assay after 6 $\mathrm{h}$ in reoxygenation in each case. In each case, the mean $\pm \mathrm{SD}$ of triplicate determinations from one experiment is shown. In $A$ and $B$, ${ }^{*}$ indicates $P<0.05$ and ${ }^{* *}$ indicates $P<0.01$ compared with $(A)$ normoxic samples in the absence of allopurinol or BHT or $(B)$ the bar marked none.

the stimulus for subsequent IL-1 production/release. Consistent with this hypothesis, addition of allopurinol early in the reoxygenation period (simultaneous with placement of cultures in normoxia or 5-10 min later) blocked IL-1 production, whereas addition of allopurinol at later times $(1-3 \mathrm{~h})$ had less effect (Fig. $5 \mathrm{~B}$ ). Similar results were observed with respect to addition of BHA and inhibition of reoxygenation-induced IL-1 production (Fig. $5 B$ ).

Production of IL-1 by freshly isolated monocytes. These experiments demonstrating IL-1 production by hypoxic/reoxygenated cultured monocyte-derived macrophages led us to perform studies with human monocytes freshly isolated from peripheral blood. After exposure of monocytes to hypoxia and 

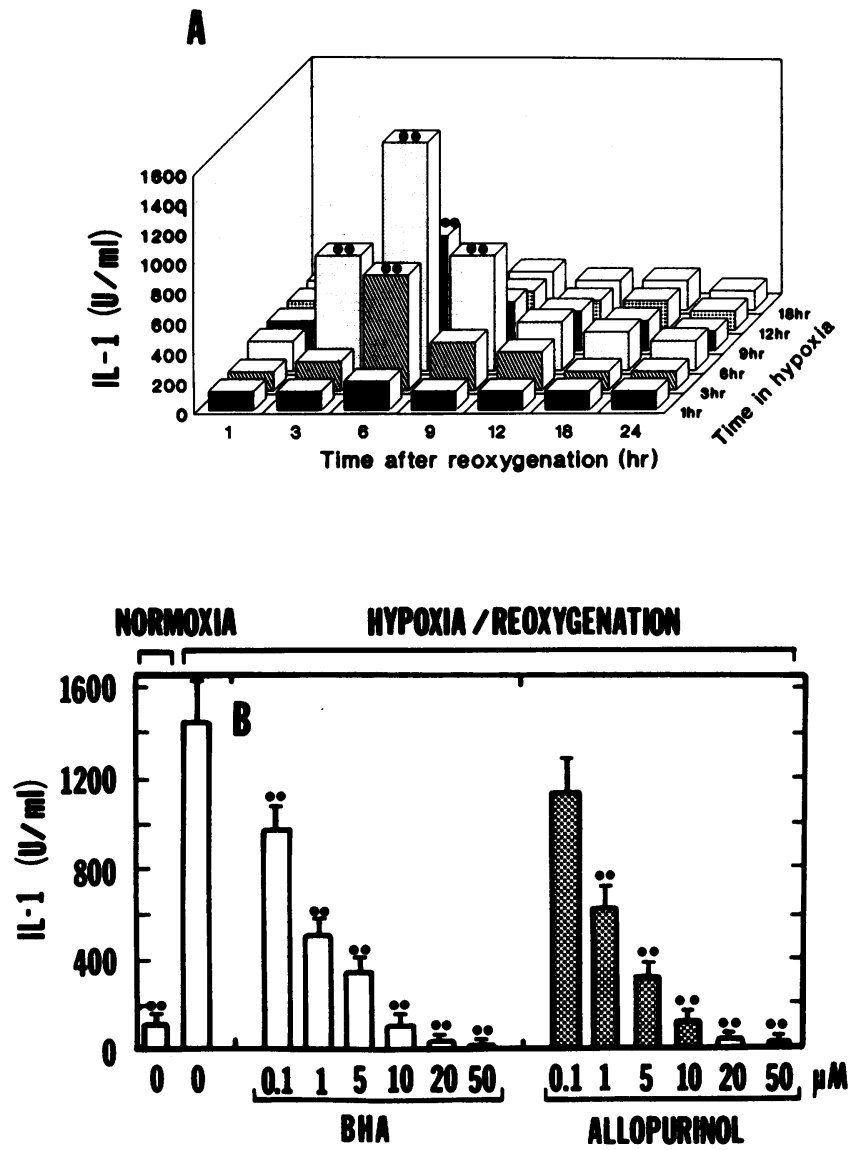

Figure 6. Monocyte production of IL-1 activity following exposure to hypoxia/reoxygenation: time course and effect of inhibitors. $(A)$ Time course. Monocytes $\left(10^{6}\right.$ cells) were exposed to hypoxia $\left(\mathrm{pO}_{2}\right.$ $\approx 14$ torr) followed by replacement into normoxia for the indicated time. Aliquots of culture supernatant were assayed for IL-1 activity. The mean of duplicate determinations from one experiment is shown. The bars marked ${ }^{* *}$ indicate $P<0.01$ compared with normoxic controls. $(B)$ IL-1 production by hypoxic/reoxygenated monocytes: effect of BHA and allopurinol. Monocytes $\left(10^{6}\right.$ cells $)$ were exposed to hypoxia ( $\mathrm{pO}_{2} \approx 14$ torr) for $6 \mathrm{~h}$ followed by normoxia for $6 \mathrm{~h}$. Where indicated, either BHA or allopurinol were added just before reoxygenation. The mean \pm SD of four determinations pooled from two experiments (each performed in duplicate) is shown. Bars marked ** indicate $P<0.01$ compared with $\mathrm{H} / \mathrm{R}(0)$.

restoration to normoxia, elaboration of substantial amounts of IL-1 activity was observed (Fig. $6 \mathrm{~A}$ ) with a time course similar to that seen with the macrophages. Baseline IL-1 production by freshly isolated human monocytes adherent to the growth surface was much greater than that for monocyte-derived macrophages (compare with baseline of normoxic macrophages in Fig. $1 C$ ). Over time in culture under normoxic conditions, elaboration of IL-1 by monocyte-derived macrophages steadily declined to the values shown in Fig. $1 C$ for normoxic cultures. Production of IL-1 by monocytes during hypoxia/reoxygenation could be blocked in a dose-dependent manner by the addition of BHA and allopurinol (Fig. $6 \mathrm{~B}$ ), suggesting that formation of oxygen free radicals was the stimulus for IL-1 elaboration. Taken together, these observations indicated that fresh monocytes, as well as macrophages, had the potential to generate IL-1 activity in response to hypoxia/reoxygenation.
IL-1 containing MP supernatants enhance endothelial adhesiveness for leukocytes and induce tissue factor expression. Since IL-1 has been shown to modulate EC-leukocyte interaction $(28)$ and to induce production of tissue factor $(21,22)$, it was important to determine if supernatants of reoxygenated MPs could perturb these EC properties. Preincubation of EC monolayers with IL-1-containing conditioned medium from reoxygenated macrophages increased the subsequent binding of leukocytes compared with monolayers exposed to macrophage supernatants from normoxic or hypoxic cultures (data not shown ). In addition, conditioned medium from reoxygenated MPs led to the induction of endothelial tissue factor, as shown by the Factor VIIa-mediated Factor X activation, which could be blocked by anti-tissue factor antibody (data not shown).

Effect of hypoxia/reoxygenation on production of TNF and $I L-6$ by MPs. In view of the expression of IL- 1 by MPs during reoxygenation, it was important to determine if other cytokines, especially TNF and/or IL-6, were also produced at the same time. When macrophages were exposed to hypoxia/reoxygenation under conditions that led to optimal production of IL-1, no TNF antigen was evident in culture supernatants (Fig. $7 A$ ). Positive controls in which macrophages were incubated with LPS (5) in normoxia demonstrated production of TNF activity. Although LPS-induced macrophage elaboration of TNF was about the same in normoxia and hypoxia, during reoxygenation there was a considerable reduction in the amount of detectable TNF activity in conditioned media from LPS-stimulated macrophage or monocyte cultures (Fig. $7 A$ ).

Production of IL- 6 by reoxygenated macrophages was also studied using an ELISA. Neither normoxic, hypoxic, nor hypoxic/reoxygenated macrophages elaborated IL-6 antigen into culture medium at the times indicated (Fig. $7 \mathrm{~B}$ ). When the same populations of monocytes were exposed to IL- $1 \alpha$ in normoxia, production of IL-6 was evident (Fig. $7 \mathrm{~B}$ ), as described previously (29).

Effect of hypoxia/reoxygenation on $I L-1$ production in a mouse model. Our observations that monocytes and macrophages in culture elaborated IL-1 during reoxygenation led us to perform studies in an animal model to determine if IL-1 was produced in this setting in vivo. For these studies, mice were exposed to a period of hypoxia followed by reoxygenation, and plasma samples were studied for IL-1 antigen using a radioimmunoassay (Fig. 8). Although somewhat increased levels of IL-1 were found in plasma obtained during hypoxia ( 12 and 24 $h$ ), these levels only achieved significance during the reoxygenation period. In view of the clearance of IL-1 (half-time for disappearance after intravenous administration of $\approx 19 \mathrm{~min}$ and after subcutaneous administration of $1.6 \mathrm{~h}(30)$, these data suggest that IL-1 production occurred in vivo during reoxygenation and, probably, hypoxia as well. Since IL-1 elaboration by MPs in vitro occurred only several hours after reoxygenation, these in vivo observations imply that additional mechanisms (which could reflect the participation of other cells in addition to macrophages) are involved in the intact animal.

\section{Discussion}

These studies show that exposure of MPs, either freshly obtained monocytes or monocyte-derived macrophages, to a pe- 

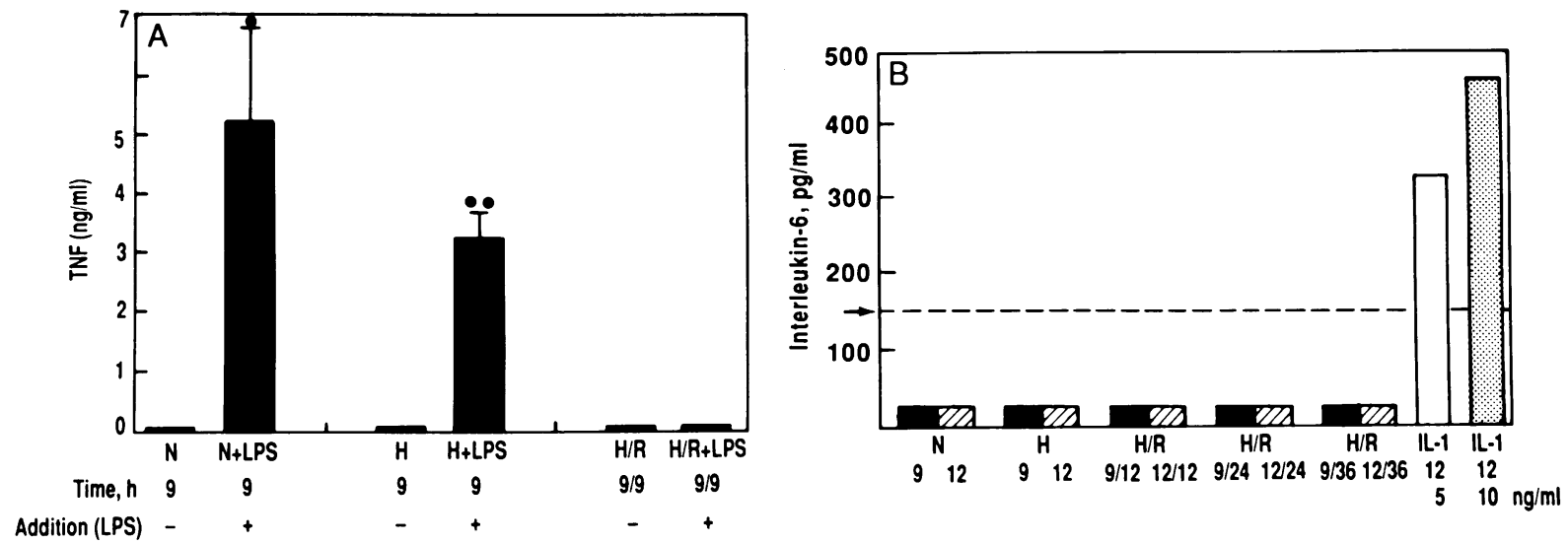

Figure 7. Elaboration of TNF and IL-6 by macrophages: effect of hypoxia and hypoxia/reoxygenation. $(A)$ Elaboration of TNF antigen. Macrophages $\left(10^{6}\right.$ cells $)$ were incubated in normoxia $(N)$, hypoxia $\left(H, \mathrm{pO}_{2} \approx 14\right.$ torr $)$, or hypoxia followed by reoxygenation $(H / R)$ for the indicated times in normal medium or medium containing LPS $(1 \mu \mathrm{g} / \mathrm{ml})$. An aliquot of culture supernatant was obtained for assessment of TNF antigen at the end of the experiment. The limit of sensitivity in the TNF ELISA was $20 \mathrm{pg} / \mathrm{ml}$. The mean \pm SD of quadruplicate determinations from one experiment is shown. The bars designated ${ }^{* *}$ and * indicate $P<0.01$ and $P<0.05$, respectively, compared with bar labeled $(N)$. $(B)$ Elaboration of IL-6 antigen. Macrophages ( $10^{6}$ cells) were incubated in normoxia, hypoxia, or hypoxia followed by reoxygenation for the indicated times as above. IL- $1 \alpha(5$ and $10 \mathrm{ng} / \mathrm{ml})$ was added for $6 \mathrm{~h}$ to one set of cultures $(I L-1)$. An aliquot of culture supernatant was obtained for assessment of IL- 6 antigen at the end of the experiment. The arrow and dashed line indicate the limit of sensitivity in the IL-6 ELISA. The mean of duplicate determinations from one experiment is shown.

riod of hypoxia followed by reoxygenation leads to the induction of IL-1 synthesis and release, probably triggered by oxygen free radicals produced early during reexposure to normoxia. Under the current conditions, viability of cultured MPs was not affected. Thus, the data support a role for the early pulse of oxygen free radicals as the stimulus for IL-1 production. The

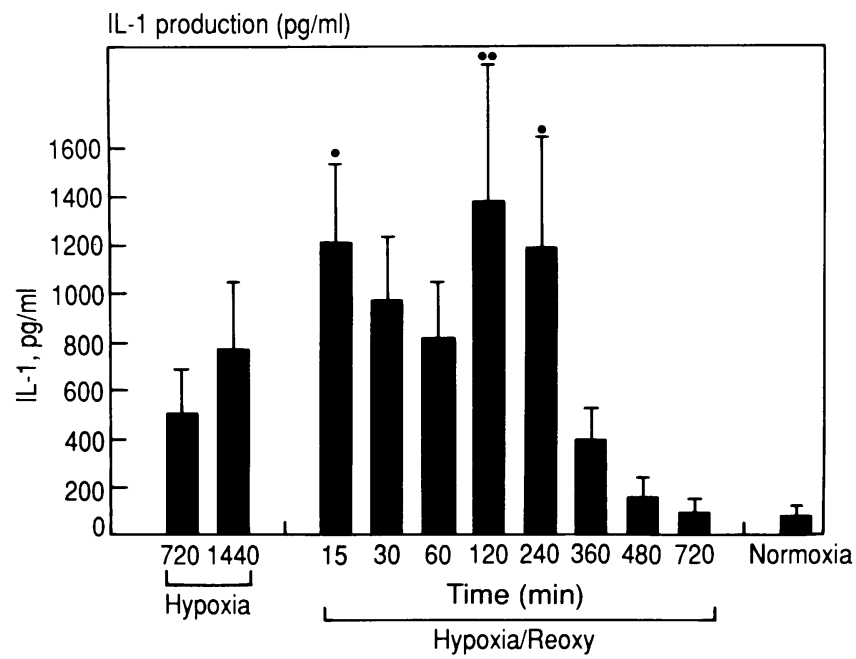

Figure 8. IL-1 antigen in the serum of mice exposed to normoxia, hypoxia, or hypoxia followed by reoxygenation. Mice were exposed to the ambient atmosphere (Normoxia; $n=4)$, hypoxia $\left(\mathrm{pO}_{2} \approx 14\right.$ torr; $720 \mathrm{~min}$ and $24 \mathrm{~h}, n=4)$, or hypoxia (1,440 $\mathrm{min}$ ) followed by replacement into the ambient atmosphere for the indicated times ( $n$ $=3$, in each case except $15 \mathrm{~min}$ and $30 \mathrm{~min}$ where $n=4$ ). Plasma samples were processed in triplicate and were assayed for IL-1 antigen ( $m e a n \pm \mathrm{SD}$ ) using the radioimmunoassay. Bars designated by * indicate $P<0.05$ and ${ }^{* *}$ indicate $P<0.01$ compared with normoxic controls. general free radical scavengers BHA and BHT, and the xanthine oxidase inhibitor allopurinol, diminished IL-1 production when added to cultures just before replacement in normoxia. In contrast, addition of inhibitors after the burst of oxygen free radical production ( $>60-120$ min after reoxygenation) did not diminish IL-1 elaboration. Although the exact species of free radical responsible for IL-1 production has not been identified, based on the studies represented in Figs. 4 and 5 , it is likely that xanthine oxidase-mediated formation of superoxide radical is involved. In the setting of ischemia, high levels of xanthine oxidase are probably present, resulting from conversion of xanthine dehydrogenase, and the substrate of the enzyme, hypoxanthine, also accumulates under the same conditions (31). Formation of hydroxyl radical may also be involved in stimulating macrophage IL-1 production, since mannitol, a hydroxyl radical scavenger, had a partial inhibitory effect on IL-1 production during reoxygenation and hydrogen peroxide had a stimulatory effect.

Elaboration of IL-1 during reoxygenation required exposure of MPs to hypoxia followed by replacement into normoxia. Immunoprecipitation demonstrated little IL- $1 \beta$ in lysates from either hypoxic or normoxic macrophages. On reoxygenation, immunoprecipitation showed IL-1 to be present in cell lysates and supernatants, and functional assays were consistent with release of IL-1. In contrast, general release of cytosolic contents, such as LDH, was not observed. At the transcriptional level, IL-1 mRNA levels appeared comparable in normoxic macrophages, which did not produce IL-1, and reoxygenated macrophages, which did elaborate IL-1. These observations are consistent with the hypothesis that hypoxia/reoxygenation specifically induces biosynthesis and release of IL-1 acting at the translational level. The apparent dissociation between mRNA levels and protein synthesis observed in adherent normoxic macrophage cultures and their counterparts during hypoxia/reoxygenation is consistent with the observations 
of Schindler et al. $(32,33)$. According to their model, certain stimuli, such as $\mathrm{C} 5 \mathrm{a}$ or cell adherence to a substrate, modulate mRNA levels of IL-1, whereas another type of stimulus, e.g., LPS, induces a translational signal. Hypoxia/reoxygenation would be a pathophysiologically relevant example of a stimulus inducing IL-1 protein synthesis. In contrast, the stimulus imparted to the cell during reoxygenation that stimulated IL-1 production did not activate TNF release, although TNF mRNA was certainly present.

The detailed mechanisms involved in the release of IL-1, a molecule devoid of a signal peptide (1), from macrophages subjected to metabolic stress remains to be elucidated. However, there may be a link between enhanced IL-1 release observed in hypoxia/reoxygenation and that which follows exposure of activated monocytes to high temperatures $\left(42^{\circ} \mathrm{C}\right)$, which has been speculated to occur via a vesicular pathway (34). Studies using cultured bovine ECs have shown that expression of certain heat-shock proteins can be blocked by addition of inhibitors of oxygen-free radical scavengers (35). In this context, LPS, which also induces synthesis/release of IL-1, has been shown to induce oxygen free radical production by peripheral blood cells $(36,37)$. This suggests that oxygen free radicals may provide an important signal priming mechanisms leading to IL-1 synthesis/release.

The functional effects of IL-1 produced by hypoxic/reoxygenated MPs on the host response were illustrated by the enhanced leukocyte adherence to the EC monolayer and induction of tissue factor EC expression. The potential importance of IL-1 derived from mononuclear cells during reoxygenation was underscored by the elevated levels of IL-1 activity detectable in mouse plasma after hypoxia/reoxygenation. These data suggest that IL-1 may contribute to the pathogenesis of the host response observed in the reperfusion syndrome and point to a potential therapeutic role for inhibitors of IL-1 action in this clinical setting. Based on the previous findings of Colletti et al. (6), indicating a protective effect of anti-TNF antibodies during hepatic ischemia/reperfusion, it may well be that antagonists of both IL-1 and TNF will be efficacious to alter the course of tissue injury in reoxygenation.

\section{Acknowledgments}

We thank Mr. Samuel Rover for his generous contribution. Dr. Gabriel Godman provided invaluable suggestions throughout the course of this work, and Dr. Peter Caldwell provided a detailed critique of our manuscript. Dr. Ramzi Cotran provided inspirational discussions at the start of this work.

This work was supported by grants from the Public Health Service (HL34625, HL42833, HL42507, and HL21006), the Council for Tobacco Research (CTR 1971 and 2101R1), the Schultz and Stony-Wold Foundations, and the New York Heart Association. D. Stern completed this work during the tenure of a Genentech-EI Award from the American Heart Association.

\section{References}

1. Dinarello, C. A. 1989. Interleukin-1 and its biologically related cytokines. Adv. Immunol. 44:153-205.
2. Flaherty, J., and M. Weisfeldt. 1988. Reperfusion injury. Free Radical Biol. Med. 5:409-419.

3. Repine, J., J. Cheronis, T. Rodell, S. Linas, and A. Patt. 1987. Pulmonary oxygen toxicity and ischemia-reperfusion injury. Am. Rev. Respir. Dis. 136:483485.

4. Van Snick, J. 1990. Interleukin-6: an overview. Annu. Rev. Immunol. 8:253-278.

5. Sherry, B., and A. Cerami. 1988. Cachectin/tumor necrosis factor exerts endocrine, paracrine, and autocrine control of inflammatory responses. J. Cell Biol. 107:1269-1277.

6. Colletti, L., D. Remick, G. Burtch, S. Kunkel, R. Strieter, and D. Campbell. 1990. Role of tumor necrosis factor- $\alpha$ in the pathophysiologic alterations after hepatic ischemia/reperfusion injury in the rat. J. Clin. Invest. 85:1936-1943.

7. Maury, C., and A.-M. Teppo. 1989. Circulating tumour necrosis factor- $\alpha$ in myocardial infarction. J. Intern. Med. 225:333-336.

8. Quinn, M., S. Parthasarathy, L. Fong, and D. Steinberg. 1987. Oxidatively modified low density lipoproteins: a potential role in recruitment and retention of monocyte/macrophages during atherogenesis. Proc. Natl. Acad. Sci. USA. 84:2995-2998.

9. Stern, D., I. Bank, P. Nawroth, J. Cassimeris, W. Kisiel, J. Fenton, C. Dinarello, E. Jaffe, and L. Chess. 1985. Self-regulation of procoagulant events on the endothelial surface. J. Exp. Med. 162:1223-1235.

10. Gunther, S., R. W. Alexander, W. Atkinson, and M. Gimbrone. 1982. Functional angiotensin II receptors in cultured vascular smooth muscle cells. $J$. Cell Biol. 92:289-298.

11. Colucci, W., T. Brock, M. Gimbrone, and R. W. Alexander. 1985. Nonlinear relationship between $\alpha_{1}$-adrenergic receptor occupancy and norepinephrine-stimulated calcium flux in cultured vascular smooth muscle cells. Mol. Pharmacol. 27:517-524.

12. Gown, A., A. Vogel, D. Gordon, and P. Lu. 1985. A smooth muscle-specific monoclonal antibody recognizes smooth muscle actin isozymes. J. Cell Biol. 100:807-813.

13. Ogawa, S., H. Gerlach, C. Esposito, A. Pasagian-Macaulay, J. Brett, and D. Stern. 1990. Hypoxia modulates the barrier and coagulant function of cultured bovine endothelium. J. Clin. Invest. 85:1090-1098.

14. Loike, J., V. Kozler, and S. C. Silverstein. 1979. Increased ATP and creatine phosphate turnover in phagocytosing peritoneal macrophages. J. Biol. Chem. 254:9558-9564.

15. Madri, J., B. Pratt, and A. Tucker. 1988. Phenotypic modulation of endothelial cells by transforming growth factor- $\beta$ depends upon the composition and organization of the extracellular matrix. J. Cell Biol. 106:1375-1384.

16. Totter, J. E. de Dugros, and C. Riverivo. 1960. The use of chemiluminescent compounds as possible indicators of radical production during xanthine oxidase action. J. Biol. Chem. 235:1839-1846.

17. Humphreys, M., and S. Hopkins. 1989. Simple, sensitive and specific bioassay of interleukin 1. J. Immunol. Methods. 120:271-276.

18. Laemmli, U. 1970. Cleavage of structural proteins during the assembly of the head of bacteriophage T4. Nature (Lond.). 227:680-685.

19. Narayanan, R., N. Tare, W. Benjamin, and U. Gubler. 1989. A sensitive technique to monitor gene transfer and expression in bone marrow stem cells. Exp. Hematol. 17:832-835.

20. Wright, S., J. Weitz, A. Huang, S. Levin, S. C. Silverstein, and J. Loike. 1988. Complement receptor type three of human polymorphonuclear leukocytes recognizes fibrinogen. Proc. Natl. Acad. Sci. USA. 85:7734-7738.

21. Bevilacqua, M., J. Pober, J. Majeau, R. Cotran, and M. Gimbrone. 1984. Interleukin 1 induces biosynthesis and cell surface expression of procoagulant activity in human vascular endothelial cells. J. Exp. Med. 160:618-623.

22. Nawroth, P., D. Handley, C. Esmon, and D. Stern. 1986. Interleukin 1 induces endothelial cell procoagulant while suppressing cell surface anticoagulant activity. Proc. Natl. Acad. Sci. USA. 83:3460-3464.

23. Beuscher, H., C. Gunther, and M. Rollinghoff. 1990. IL- $1 \beta$ is secreted by activated murine macrophages as biologically inactive precursor. J. Immunol. 144:2179-2183.

24. Suttles, J., J. Carruth, and S. Mizel. 1990. Detection of IL-1 $\alpha$ and IL-1 $\beta$ in the supernatants of paraformaldehyde-treated human monocytes. J. Immunol. 144:170-174.

25. Moorhouse, P., M. Grootveld, B. Halliwell, J. Quinlan, and J. Gutteridge. 1987. Allopurinol and oxypurinol are hydroxyl radical scavengers. FEBS (Fed. Eur. Biochem. Soc.) Lett. 213:23-28.

26. Graf, E., J. Mahoney, R. Bryant, and J. Eaton. 1984. Iron catalyzed hydroxyl radical formation. J. Biol. Chem. 259:3620-3624.

27. Aust, S., and B. Svingen. 1982. The role of iron in enzymatic lipid peroxidation. Free Radicals Biol. V:1-28.

28. Bevilacqua, M., S. Stengeli, M. Gimbrone, and B. Seed. 1989. Endothelia leukocyte adhesion molecule 1: an inducible receptor for neutrophils related to complement regulatory proteins and lectins. Science (Wash. DC). 243:11601165. 
29. Tosato, G., and K. Jones. 1990. Interleukin-1 induces interleukin-6 production in peripheral blood monocytes. Blood. 75:1305-1310.

30. Kudo, S., K. Mizuno, Y. Hirai, and T. Shimizu. 1990. Clearance and tissue distribution of recombinant human interleukin $1 \beta$ in rats. Cancer Res. 50:5751-5755.

31. McCord, J. 1985. Oxygen-derived free radicals in postischemic tissue injury. N. Engl. J. Med. 312:159-163.

32. Schindler, R., B. Clark, and C. Dinarello. 1990. Dissociation between interleukin- $1 \beta$ mRNA and protein synthesis in human peripheral blood mononuclear cells. J. Biol. Chem. 265:10232-10237.

33. Schindler, R., J. Gelfand, and C. Dinarello. 1990. Recombinant C5a stimulates transcription rather than translation of interleukin-1 and tumor necrosis factor. Translational signal provided by lipopolysaccharide or interleukin 1 itself. Blood. 76:1631-1638.
34. Rubartelli, A., F. Cozzolino, M. Talio, and R. Sitia. 1990. A novel secretory pathway for interleukin-1 $\beta$, a protein lacking a signal sequence. $E M B O(E u r$. Mol. Biol. Organ.) J. 9:1503-1510.

35. Ketis, N., and M. Karnovsky. 1988. Heat-shock response as a possible model for pathophysiological stress in endothelial cells. In Endothelial Cell Biology in Health and Disease. N. Simionescu and M. Simionescu, editors. Plenum, New York. 309-334.

36. Reichle, H., D. Langner, P. Wendt, and G. Blumel. 1987. Endotoxin-induced generation of oxygen free radicals in freshly drawn human blood. Prog. Clin. Biol. Res. 236:419-426.

37. Zheng, H., J. Crowley, J. Chan, and T. Raffin. 1991. Attenuation of LPS-induced neutrophil thromboxane $B_{2}$ release and chemiluminescence. $J$. Cell. Physiol. 146:264-269. 